\title{
Nuclear Cloning, Epigenetic Reprogramming, and Cellular Differentiation
}

\author{
R. Jaenisch, ${ }^{* \dagger}$ K. Hochedlinger, ${ }^{*}$ R. Blelloch, ${ }^{*}$ Y. Yamada, ${ }^{*}$ K. Baldwin, ${ }^{\ddagger}$ and K. EgGan ${ }^{* \dagger}$ \\ ${ }^{*}$ Whitehead Institute for Biomedical Research, Cambridge, Massachusetts 02142; 'Department of Biology, \\ Massachusetts Institute of Technology, Cambridge, Massachusetts 02139; ${ }^{*}$ Department of Biochemistry and \\ Molecular Biophysics, Columbia University, New York, New York 10032
}

\begin{abstract}
Almost half a century ago the technique of nuclear transplantation (NT) was pioneered in amphibians (Gurdon 1999; Di Berardino et al. 2003). These experiments demonstrated that nuclei of somatic cells are totipotent but that the ability to generate live animals decreases with the developmental age of the donor nucleus. The generation of Dolly from an adult mammary gland cell demonstrated that at least some cells within an adult organism retain totipotency and are able to direct development of a new animal (Wilmut et al. 1997). After Dolly, additional mammalian species were successfully cloned from somatic cells, albeit with a low efficiency, as in most cases only $0.5-10 \%$ of reconstructed oocytes develop into apparently healthy adults (Rideout et al. 2001).
\end{abstract}

Epigenetic regulation of gene expression is recognized to be one of the key mechanisms governing embryonic development and cellular differentiation and, when misdirected, can lead to disease. Therefore, it is of major interest to define the specific epigenetic states that distinguish between the genomes of embryonic, somatic, and diseased cells. In normal development the process of differentiation from embryonic to differentiated cells involves alterations in the epigenetic conformation of the genome, such as DNA methylation or chromatin modifications (Li 2002; Jaenisch and Bird 2003).

In disease, abnormal modifications to chromatin can contribute to the malignant transformation of cells. For example, epigenetic changes can promote cell proliferation, inhibit apoptosis, and induce angiogenesis during tumorigenesis by activating oncogenes and silencing tumor suppressor gene (Jones and Baylin 2002; Felsher 2003). Thus, we have to understand the epigenetic states that distinguish the genome of embryonic cells from that of different somatic cells and transformed cells (see Fig. 1). To alter the phenotype of cells in a rational way we first need to define the molecular parameters that distinguish these different cell types. Nuclear cloning represents an unbiased tool to begin unraveling these mechanisms as it provides a functional readout of the epigenetic changes induced by the egg cytoplasm. In this paper, we will summarize recent work from our laboratory that focuses on the relation between the state of differentiation and the efficiency of epigenetic reprogramming by nuclear transfer. This is relevant for the possible therapeutic applications of the nuclear transfer technology. Moreover, we will discuss the potential use of nuclear transfer for studying the genome of cancer cells. This review is largely based upon summaries of our work in a review commissioned by the President's Council on Bioethics (Jaenisch 2004) and in the Proceedings of a recent Novartis conference (Jaenisch et al. 2004).

\section{EPIGENETIC REPROGRAMMING IN NORMAL DEVELOPMENT AND AFTER NUCLEAR TRANSFER}

The majority of cloned mammals derived by nuclear transfer (NT) die during gestation, display neonatal phenotypes resembling "Large Offspring Syndrome" (Young et al. 1998), often with respiratory and metabolic abnormalities, and have enlarged and dysfunctional placentas (Rideout et al. 2001). In order for a donor nucleus to support development into a clone, it must be reprogrammed to a state compatible with embryonic development. The transferred nucleus must properly activate genes important for early embryonic development and also suppress differentiation-associated genes that had been transcribed in the original donor cell. Inadequate "reprogramming" of the donor nucleus is thought to be the principal reason for developmental failure of clones. Since few clones survive to birth, the question remains whether survivors are

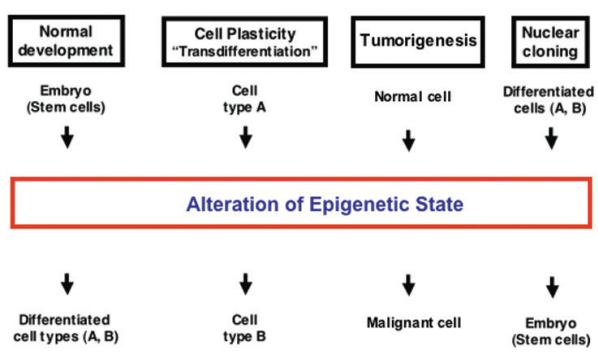

Figure 1. Importance of epigenetic changes during cellular differentiation, transformation, and nuclear cloning. Epigenetic alterations are essential during normal development when embryonic cells give rise to all differentiated cell types of the body. Epigenetic changes may also be involved in the "transdifferentiation" of one differentiated cell type into another differentiated cell type. In addition, epigenetics plays an important role in the malignant transformation of cells by activating oncogenes and silencing tumor suppressor genes. Conversely, nuclear transfer can globally reprogram the epigenetic state of a differentiated cell into that of an embryonic (stem) cell. 
normal or merely the least severely affected animals, making it to adulthood despite harboring subtle abnormalities originating from faulty reprogramming (Rideout et al. 2001).

Evidence obtained over the last few years has given insights into molecular changes that are abnormal in cloned as compared to normal animals. Table 1 summarizes some of the epigenetic differences that distinguish cloned from normal animals as result of faulty reprogramming. For the following discussion it is useful to compare the different stages of development following nuclear transplantation. The stages of development that are depicted in Table 1 and that will be discussed in sequence are (i) gametogenesis, (ii) cleavage, (iii) postimplantation, and (iv) postnatal development.

(i) The most important epigenetic reprogramming in normal development occurs during gametogenesis, a process that renders both sperm and oocyte genomes "epigenetically competent" for subsequent fertilization and for faithful activation of the genes that are crucial for early development (Latham 1999; Rideout et al. 2001). In cloning, this process is shortcut and most problems affecting the "normalcy" of cloned animals may be due to the inadequate reprogramming of the somatic nucleus following transplantation into the egg. Since the placenta is derived from the trophectoderm lineage that constitutes the first differentiated cell type of the embryo, one might speculate that reprogramming and differentiation into this early lineage are compromised in most cloned animals. Indeed, results obtained in our laboratory and by others indicate that the fraction of abnormally expressed genes in cloned newborns is substantially higher in the placenta as compared to somatic tissues (Humpherys et al. 2002; Fulka et al. 2004). In contrast to epigenetic reprogramming that occurs prezygotically, it appears that postzygotic reprogramming such as X-chromosome inactivation (Eggan et al. 2000) and telomere length adjustment (Lanza et al. 2000; Tian et al. 2000; Wakayama et al. 2000; Betts et al. 2001) are faithfully accomplished after nuclear transfer and, therefore, would not be expected to impair survival of cloned animals. (ii) During cleavage, a wave of genome-wide demethylation removes the epigenetic modification present in the zygote so that the DNA of the blastocyst is largely devoid of methylation. Between implantation and gastrulation, a wave of global de novo methylation reestablishes the overall methylation pattern, which is then maintained throughout life in the somatic cells of the animal (Monk et al. 1987; Jaenisch 1997; Reik et al. 2001). In cloned embryos abnormal methylation at repetitive sequences (Kang et al. 2001) and frequent failure to reactivate Fgf4, Fgf2r, and IL6 (Daniels et al. 2000) have been observed. To investigate gene expression, the activity of "pluripotency genes," such as Oct4, that are silent in somatic cells but active in embryonic cells was examined in cloned embryos. Strikingly, the reactivation of Oct-4 (Boiani et al. 2002; Bortvin et al. 2003) and of "Oct-4-like" (Bortvin et al. 2003) genes was shown to be faulty and random in somatic clones. Because embryos lacking Oct-4 arrest early in development (Nichols et al. 1998), incomplete reactivation of Oct-4-like genes in clones might be a cause of the frequent failure of the great majority of NT embryos to survive the postimplantation period. Also, a number of studies have detected abnormal DNA methylation in cloned embryos (Bourc'his et al. 2001; Kang et al. 2002; Santos et al. 2002; Mann et al. 2003). Though it is still an unresolved question to what extent the epigenetic modification of chromatin structure and DNA methylation, which occurs in normal development, needs to be mimicked for nuclear cloning to succeed, the available evidence is entirely consistent with faulty epigenetic reprogramming causing the abnormal gene expression in cloned animals.

(iii) The most extensive analysis of gene expression has been performed in newborn cloned mice. Expression profiling showed that $4-5 \%$ of the genome and between $30 \%$ and $50 \%$ of imprinted genes are abnormally expressed in placentas of newborn cloned mice (Humpherys et al. 2002). This argues that mammalian development is surprisingly tolerant to widespread gene dysregulation and that compensatory mechanisms assure survival of some clones to birth. However, the results suggest that even sur-

Table 1. Normal versus Cloned Embryos

\begin{tabular}{|c|c|c|c|}
\hline Stage & Normal embryos & Cloned embryos & References \\
\hline Gametogenesis & $\begin{array}{l}\text { Genome "competent" for } \\
\text { activation of "early" genes, } \\
\text { establishment of imprints }\end{array}$ & None & \\
\hline Cleavage & $\begin{array}{l}\text { Global demethylation } \\
\text { Activation of embryonic } \\
\text { ("Oct4-like") genes }\end{array}$ & $\begin{array}{l}\text { Abnormal methylation } \\
\text { Stochastic / faulty activation } \\
\text { of "Oct4-like" genes }\end{array}$ & $\begin{array}{l}1 \\
2\end{array}$ \\
\hline \multirow[t]{2}{*}{ Postimplantation } & \multicolumn{2}{|c|}{$\begin{array}{l}\text { Global de novo methylation, } \\
\text { X-inactivation, telomere length } \\
\text { adjustment (postzygotic events) }\end{array}$} & 3 \\
\hline & $\begin{array}{l}\text { Normal imprinting } \\
\text { and gene expression }\end{array}$ & $\begin{array}{l}\text { Abnormal imprinting, } \\
\text { global gene dysregulation }\end{array}$ & 4 \\
\hline Postnatal & Normal animal & $\begin{array}{l}\text { Large offspring syndrome, } \\
\text { premature death, etc. }\end{array}$ & 5 \\
\hline
\end{tabular}

References. 1. Monk et al. 1987; Bourc'his et al. 2001; Dean et al. 2001, 2003; Kang et al. 2002. 2. Boiani et al. 2002; Bortvin et al. 2003. 3. Eggan et al. 2000; Lanza et al. 2000; Tian et al. 2000; Wakayama et al. 2000; Betts et al. 2001. 4. Humpherys et al. 2002; Fulka et al. 2004. 5. Young et al. 1998; Ogonuki et al. 2002; Tamashiro et al. 2002; Hochedlinger and Jaenisch 2003. 
viving clones may have subtle defects that, though not severe enough to jeopardize immediate survival, will cause an abnormal phenotype at a later age.

(iv) The generation of adult and seemingly healthy adult cloned animals has been taken as evidence that nuclear transfer can generate normal cloned animals, albeit with low efficiency. Indeed, a routine physical and clinical laboratory examination of 24 cloned cows of 1-4 years of age failed to reveal major abnormalities (Lanza et al. 2001). Cloned mice of a corresponding age as that of the cloned cows (2-6 mon in mice vs. 1-4 years in cows) also appear "normal" by superficial inspection. However, when cloned mice were aged, serious problems, not apparent at younger ages, became manifest. One study found that the great majority of cloned mice died significantly earlier than normal mice, succumbing with immune deficiency and serious pathological alterations in multiple organs (Ogonuki et al. 2002). Another study found that aged cloned mice became overweight with major metabolic disturbances (Tamashiro et al. 2002). Thus, serious abnormalities in cloned animals may often become manifest only when the animals age. This raises the question: Is it possible to produce truly "normal" clones?

\section{"Normal" Clones: Do They Exist?}

A key question in the public debate over cloning is whether it would ever be possible to produce a normal individual by nuclear cloning. The available evidence suggests that it may be difficult if not impossible to produce normal clones for the following reasons. (1) As summarized above, all analyzed clones at birth showed dysregulation of hundreds of genes. The development of clones to birth and beyond despite widespread epigenetic abnormalities suggests that mammalian development can tolerate dysregulation of many genes. (2) Some clones survive to adulthood by compensating for gene dysregulation. Though this "compensation" assures survival, it may not prevent maladies from becoming manifest at later ages. Therefore, most, if not all, clones are expected to have at least subtle abnormalities that may not be severe enough to result in an obvious phenotype at birth but will cause serious problems later, as seen in aged mice. Different clones may just differ in the extent of abnormal gene expression: If the key "Oct-4-like" genes are not activated (Bortvin et al. 2003), clones die immediately after implantation. If those genes are activated, the clone may survive to birth and beyond.

As schematically shown in Figure 2, the two stages when the majority of clones fail are immediately after implantation and at birth. These are two critical stages of development that may be particularly vulnerable to faulty gene expression. Once cloned newborns have progressed through the critical perinatal period, various compensatory mechanisms may counterbalance abnormal expression of other genes that are not essential for the subsequent postnatal survival. However, the stochastic occurrence of disease and other defects at later age in many or most adult clones implies that such compen-

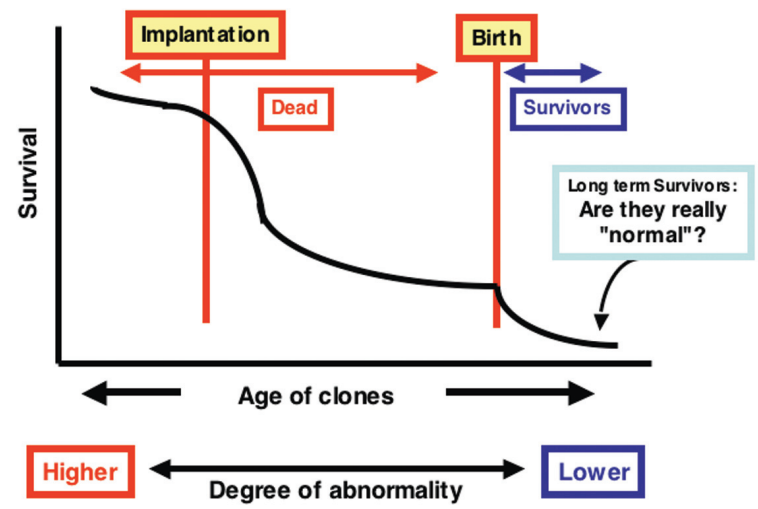

Figure 2. The phenotypes are distributed over a wide range of abnormalities. Most clones fail at two defined developmental stages, implantation and birth. More subtle gene expression abnormalities result in disease and death at later ages.

satory mechanisms do not guarantee "normalcy" of cloned animals. Rather, the phenotypes of surviving cloned animals may be distributed over a wide spectrum from abnormalities causing sudden demise at later postnatal age or more subtle abnormalities allowing survival to advanced age (Fig. 2). These considerations illustrate the complexity of defining subtle gene expression defects and emphasize the need for more sophisticated test criteria such as environmental stress or behavior tests.

\section{Is It Possible to Overcome the Problems Inherent in Reproductive Cloning?}

It is often argued that the "technical" problems in producing normal cloned mammals will be solved by scientific progress that will be made in the foreseeable future. The following considerations argue that this may not be so.

A principal biological barrier that prevents clones from being normal is the "epigenetic" difference between the chromosomes inherited from mother and from father (i.e., the difference between the "maternal" and the "paternal" genome of an individual). DNA methylation is an example of such an epigenetic modification that is known to be responsible for shutting down the expression of nearby genes. Parent-specific methylation marks are responsible for the expression of "imprinted genes" and cause only one copy of an imprinted gene, derived either from sperm or egg, to be active while the other allele is inactive (Ferguson-Smith and Surani 2001). When sperm and oocyte genomes are combined at fertilization, the parent-specific marks established during oogenesis and spermatogenesis persist in the genome of the zygote (Fig. 3A). Of interest for this discussion is that within hours after fertilization, most of the global methylation marks (with the exception of those on imprinted genes) are stripped from the sperm genome whereas the genome of the oocyte is resistant to this active demethylation process (Mayer et al. 2000; Oswald et al. 2000). This is because the oocyte genome is in a different "oocyte-appropriate" epigenetic state than the 


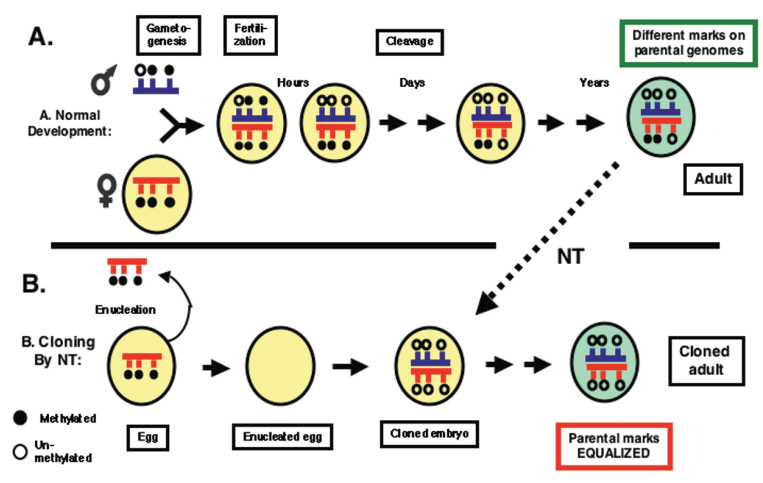

Figure 3. Parental epigenetic differences in normal and cloned animals. $(A)$ The genomes of oocyte and sperm are differentially methylated during gametogenesis and are different in the zygote when combined at fertilization. Immediately after fertilization the paternal genome (derived from the sperm) is actively demethylated whereas the maternal genome is only partially demethylated during the next few days of cleavage. This is because the oocyte genome is in a different chromatin configuration and is resistant to the active demethylation process imposed on the sperm genome by the egg cytoplasm. Thus, the methylation of two parental genomes is different at the end of cleavage and in the adult. Methylated sequences are depicted as filled lollipops and unmethylated sequences as empty lollipops. (B) In cloning a somatic nucleus is transferred into the enucleated egg and both parental genomes are exposed to the active demethylating activity of the egg cytoplasm. Therefore, the parent specific epigenetic differences are equalized.

sperm genome. The oocyte genome becomes only partially demethylated within the next few days by a passive demethylation process. The result of these postfertilization changes is that the two parental genomes are epigenetically different (as defined by the patterns of DNA methylation) in the later-stage embryo and remain so in the adult in imprinted as well as nonimprinted sequences.

In cloning, the epigenetic differences established during gametogenesis may be erased because both parental genomes of the somatic donor cell are introduced into the egg from the outside and are thus exposed equally to the demethylation activity present in the egg cytoplasm (Fig. $3 \mathrm{~B})$. This predicts that imprinted genes should be particularly vulnerable to inappropriate methylation and associated dysregulation in cloned animals. The results summarized earlier are consistent with this prediction. For cloning to be made safe, the two parental genomes of a somatic donor cell would need to be physically separated and separately treated in an "oocyte-appropriate" and a "sperm-appropriate" way, respectively. At present, it seems that this is the only rational approach to guarantee the creation of the epigenetic differences that are normally established during gametogenesis. Such an approach is beyond our present abilities. These considerations imply that serious biological barriers exist that interfere with faithful reprogramming after nuclear transfer. It is a safe conclusion that these biological barriers represent a major stumbling block to efforts aimed at making nuclear cloning a safe reproductive procedure for the foreseeable future (Jaenisch 2004).

\section{DERIVATION OF CLONED ANIMALS FROM TERMINALLY DIFFERENTIATED CELLS}

A question already raised in the seminal cloning experiments with amphibians was whether terminal differentiation would diminish the potency of a nucleus to direct development after transfer into the oocyte (Di Berardino 1980; Gurdon 1999). The recent isolation of rare adult stem cells from somatic tissues and reports of their developmental plasticity raise an important question: Do viable clones predominantly or exclusively result from adult stem cells randomly selected from the donor cell population (Hochedlinger and Jaenisch 2002b)? These cells might be similar to embryonic stem (ES) cells that require less reprogramming and support postimplantation development with high efficiency. In order to better define the influence of the donor nucleus on the development of cloned animals, we have compared cells of different developmental stages for their potency to serve as nuclear donors.

Table 2 summarizes the potential of blastocysts derived from normal zygotes with that derived from ES cell and somatic donor cell nuclei after transfer into oocytes. The results show that ES NT embryos develop to term at a 10-20-fold higher efficiency than embryos from cumulus or fibroblast donor cells. The main conclusion that can be drawn from the observations summarized in Table 2 is that the nucleus of an undifferentiated embryonic cell is more amenable to, or requires less reprogramming than, the nucleus of a differentiated somatic cell. The epigenetic (or pluripotent) state of the genome in an ES cell may more closely resemble that of the early embryo, which enables ES cells to serve as more effective nuclear donors. This notion was directly tested by analyzing the expression of genes active in the different donor cells with the expression pattern seen in cloned blastocysts derived from the respective donor cells (see above; Bortvin et al. 2003).

Assuming that the epigenetic state of somatic stem cells resembles that of embryonic stem cells it appears possible that most surviving clones could be derived from nuclei of rare somatic stem cells present in the heterogeneous donor cell population rather than from nuclei of differentiated somatic cells as has been assumed (Liu 2001; Hochedlinger and Jaenisch 2002b; Oback and Wells 2002). Because in previous experiments no unambiguous marker had been used that would retrospectively identify the donor nucleus, this possibility could not be excluded.

Table 2. Higher Survival of Mice Cloned from ES Cell Donor Nuclei as Compared to Somatic Donor Cell Nuclei

\begin{tabular}{lcc}
\hline Donor cells & $\begin{array}{c}\text { Survival to adults } \\
\text { (from cloned blastocysts) (\%) }\end{array}$ & References \\
\hline Cumulus & $1-3$ & 1 \\
Fibroblasts & $0.5-1$ & 1 \\
Sertoli cells & $1-3$ & 1 \\
B, T cells, neurons & $<0.001$ & 2 \\
ES cells & $15-25$ & 3 \\
\hline
\end{tabular}

References. 1. Wakayama and Yanagimachi 1999, 2001. 2. Hochedlinger and Jaenisch 2002a; Eggan et al. 2004; Li et al. 2004. 3. Eggan et al. 2001. 
Thus, it had not been resolved whether the genome of a truly terminally differentiated cell could be reprogrammed to an embryonic state. To address this issue, we used nuclei from mature $\mathrm{B}$ and $\mathrm{T}$ cells and from terminally differentiated neurons as donors to generate cloned mice.

\section{Monoclonal Mice from Mature Immune Cells}

The monoclonal mice were generated from nuclei of peripheral lymphocytes where the genetic rearrangements of the immunoglobulin and TCR genes could be used as stable markers revealing the identity and differentiation state of the donor nucleus of a given clone. Because previous attempts to generate monoclonal mice had been unsuccessful (Wakayama and Yanagimachi 2001), we used a two-step cloning procedure by producing, first, embryonic stem (ES) cells from cloned blastocysts and, in a second step, monoclonal mice by tetraploid-embryo complementation (Fig. 4) (Nagy et al. 1993; Eggan et al. 2001). Animals generated from a B or $\mathrm{T}$ cell donor nucleus were viable and carried fully rearranged immunoglobulin or $\mathrm{T}$ cell receptor genes in all tissues (Hochedlinger and Jaenisch 2002a). As expected, the immune cells of the monoclonal mice expressed only those alleles of the Ig and TCR locus that had been productively rearranged in the respective donor cells used for nuclear transfer and the rearrangements of other Ig or TCR genes was inhibited.

Our results allow two main conclusions. (i) They constitute the first unequivocal demonstration that nuclei from terminally differentiated donor cells can be reprogrammed to pluripotency by nuclear cloning. The frequency of directly deriving cloned embryos from mature $\mathrm{B}$ and $\mathrm{T}$ cells (instead of the two-step procedure used in our experiments), while difficult to estimate, is likely significantly lower than that of deriving clones from fibroblasts or cumulus cells (possibly less than 1 in 2000 operated embryos; Table 2). This is consistent with the notion that genomic reprogramming of a terminally differentiated cell may be extremely inefficient. (ii) Nuclear cloning

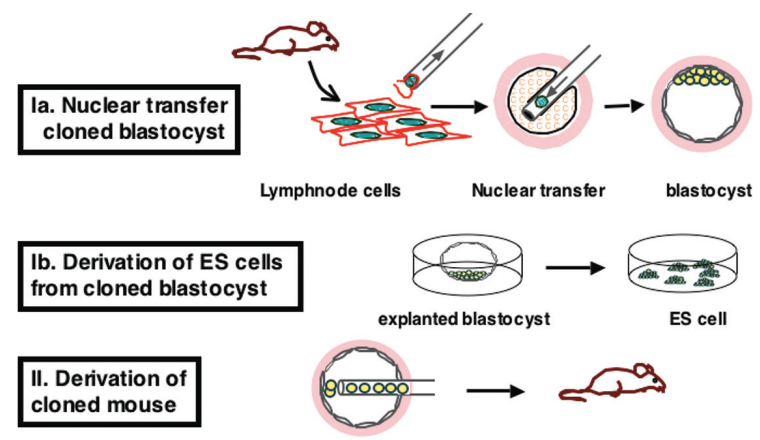

Figure 4. Two-step procedure for the derivation of monoclonal mice from mature lymphoid donor cells. (I) Nuclei from peripheral lymph node cells were transferred into enucleated eggs and cloned blastocysts were derived. The blastocysts were explanted in vitro and cloned ES cells were derived. (II) In a second step, monoclonal mice were derived by tetraploid complementation (Eggan et al. 2001; Hochedlinger and Jaenisch 2002a). allows the detection of even subtle genetic alterations within a single cell. This is of potential medical interest, as the cloning of somatic cells taken from a patient suffering of a complex disease, such as Parkinson's or diabetes, would generate ES cells that are isogenic to the patient. In vitro differentiation of these ES cells into dopaminergic neurons or beta cells, respectively, may provide an experimental in vitro system to study a complex human disease for which no animal model is available.

\section{Cloned Mice from Mature Olfactory Neurons}

Nuclei from postmitotic cells that have irreversibly exited the cell cycle as part of their program of differentiation have not been demonstrated to retain the capacity to direct embryogenesis in mammalian cloning experiments. These considerations have led to the suggestion that postmitotic cells might be refractory to epigenetic reprogramming or alternatively might have acquired changes in the DNA that could limit their developmental potential (Rehen et al. 2001). Consistent with this notion are previous experiments that failed to generate live mice from neurons (Yamazaki et al. 2001). This lead to the suggestion that the DNA of postmitotic neurons might undergo rearrangements to generate neural diversity and that these changes in DNA sequence may prevent these nuclei from reentering the cell cycle and directing embryogenesis (Vassar et al. 1993; Zhang and Firestein 2002). One particularly clear example of neuronal diversity is provided by the olfactory sensory epithelium. In the mouse, each of the two million cells in the olfactory epithelium expresses only 1 of $\sim 1500$ odorant receptor (OR) genes such that the functional identity of a neuron is defined by the nature of the receptor it expresses. The pattern of receptor expression is apparently random within one of four zones in the epithelium suggesting that the choice of receptor gene may be stochastic. One mechanism to permit the stochastic choice of a single receptor could involve DNA rearrangements (Chun and Schatz 1999).

We have generated fertile adult mouse clones by transferring the nuclei of postmitotic olfactory neurons into enucleated oocytes (Eggan et al. 2004). In a similar approach as used for the generation of the monoclonal mice (see Fig. 4), in a first step ES cells were derived from the cloned blastocyst and cloned mice were derived subsequently by tetraploid complementation. As summarized in Table 2, the efficiency of deriving cloned ES cells from olfactory neurons was in the same range as that for nuclei from immune cells. These observations indicate that a postmitotic neuronal nucleus can reenter the cell cycle and can be reprogrammed to pluripotency. A more recent study confirmed these results (Li et al. 2004).

The generation of mice cloned from a mature olfactory neuron allowed investigating whether OR choice involves irreversible DNA rearrangements. Mice were cloned from an olfactory neuron that expressed one allele of the P2 gene (which is one of the 1500 OR genes in the repertoire). The appropriate neurons for nuclear transfer were picked under the fluorescent microscope because the donor mice carried a green fluorescent protein (GFP) 


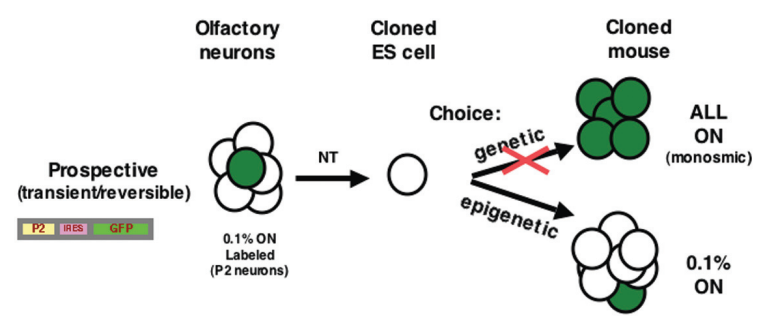

Figure 5. Nuclear cloning of mature olfactory neurons.

marker inserted into the $\mathrm{P} 2$ gene rendering the $\mathrm{P} 2$ neurons fluorescent. If OR choice involved DNA rearrangements, the prediction would be, in analogy to the monoclonal mice described above, that a mouse cloned from a P2-expressing neuron would express this receptor in all olfactory neurons and the repertoire of receptor expression might be altered (Fig. 5). Alternatively, if OR choice involved a reversible epigenetic mechanism the cloned animals should have an identical P2 expression pattern to the donor mouse and a normal repertoire of receptor expression. An exhaustive analysis of OR expression showed that the OR repertoire in the cloned mice was indistinguishable from that of wt mice. In addition, the DNA of mice derived from sensory neurons revealed no evidence for rearrangements of the expressed $\mathrm{P} 2$ olfactory receptor gene. These results indicate that the mechanism of OR choice is fully reversible and does not involve genetic alterations as seen in the maturation of $\mathrm{B}$ and $\mathrm{T}$ cells.

\section{TOTIPOTENCY OF NEURONAL NUCLEI}

The two-step cloning procedure used to produce mice from neuronal nuclei generates mice in which the neuronal-derived ES cells give rise to all embryonic tissues while cells from the tetraploid host blastocyst contribute the embryonic trophectoderm (Eggan et al. 2001). Thus, cloning of lymphocytes or neurons via an ES cell intermediate did not reveal totipotency of a nucleus from a terminally differentiated cell (Rossant 2002). To demonstrate totipotency of mature olfactory sensory neuron (OSN) nuclei, we transplanted nuclei from the cloned ES cells into enucleated oocytes to generate recloned mice (Eggan et al. 2004). The cloned pups had enlarged placentas but displayed no overt anatomic or behavioral abnormalities and survived to fertile adults, consistent with previous cloning experiments (Eggan et al. 2001). These observations demonstrate that nuclei of terminally differentiated olfactory neurons can be reprogrammed to totipotency directing development of both embryonic and extraembryonic lineages.

\section{REPROGRAMMING OF CANCER NUCLEI BY NUCLEAR TRANSPLANTATION}

The cloning of mice from terminally differentiated lymphocytes and postmitotic neurons has demonstated that nuclear transfer provides a tool to selectively repro- gram the epigenetic state of a cellular genome without altering its genetic constitution (Hochedlinger and Jaenisch 2002a; Eggan et al. 2004). Thus, nuclear transfer allows one to globally analyze the impact of epigenetics on the malignant state of a cancer cell. Historic experiments in frogs have demonstrated that kidney carcinoma nuclei can be reprogrammed to support early development to the tadpole stage (McKinnell et al. 1969). A similar result was recently obtained in mice, where nuclei from a medulloblastoma cell line were able to direct early development, albeit with low efficiency, resulting in arrested embryos (Li et al. 2003). However, these experiments did not unequivocally demonstrate that the clones were derived from cancer cells as opposed to contaminating nontransformed cells (Carlson et al. 1994). Moreover, the experimental setup did not allow the distinction between abnormalities caused by the nuclear transfer procedure versus abnormalities caused by the donor nucleus.

We have used nuclear transfer as a functional assay to determine whether the genomes of different cancer cells can be reprogrammed by the oocyte environment into a pluripotent embryonic state. Following nuclear transfer of different tumor cells, clones were allowed to develop to blastocysts and then explanted in tissue culture to derive ES cells. The resulting ES cells (hereafter denoted as NT ES cells) were then analyzed to confirm the tumor cell origin and tested in multiple assays for their developmental and tumorigenic potential. This modified cloning procedure (i) circumvents abnormalities associated with nuclear transfer (Hochedlinger and Jaenisch 2003) and (ii) permits a detailed analysis of the developmental (Hochedlinger and Jaenisch 2002a; Rideout et al. 2002; Eggan et al. 2004) and tumorigenic potential of the reprogrammed nucleus.

We have shown that the nuclei of leukemia, lymphoma, breast cancer, and melanoma cells were able to support preimplantation development into normal-appearing blastocysts and hence differentiation into the first two cell lineages of the embryo, the epiblast and trophectoderm, without signs of abnormal proliferation. Therefore, the malignant phenotype of these tumor types can be suppressed by the oocyte environment and permit apparently normal early development. However, none of the blastocysts cloned from four different hematopoietic tumors (1095 nuclear transfers) and a breast cancer cell line (189 nuclear transfers) produced NT ES cell lines after explantation in culture. Only the genome from a doxycycline-inducible RAS melanoma model gave rise to two NT ES cell lines from a total of 590 nuclear transfer experiments (Hochedlinger et al. 2004). These ES cells were able to differentiate into most, if not all, somatic cell lineages in teratomas and chimeras including fibroblasts, lymphocytes, and melanocytes. This occurred despite severe chromosomal changes documented by comparative genomic hybridization. These data suggest that the secondary chromosomal changes associated with malignancy do not necessarily interfere with preimplantation development, ES cell derivation, and a broad nuclear differentiation potential. However, chimeras produced from these embryonic stem cells developed cancer with higher 
penetrance, shorter latency, and an expanded tumor spectrum when compared with the donor mouse model. That is, all the chimeras developed melanomas shortly after induction of RAS. Interestingly, they also developed other malignant tumors including rhabdomyosarcomas and a malignant peripheral nerve sheath tumor. These later tumors had constitutively activated RAS and showed an identical comparative genomic hybridization profile as the melanomas suggesting shared genetic pathways among these very different tumor types.

In contrast to the melanoma model, we found that whereas the transfer of nuclei from embryonal carcinoma cells resulted in morphologically normal blastocysts from which ES cell lines could be produced with high efficiency, the resulting ES cells had the same developmental and tumorigenic potential as the parental EC cell lines (Blelloch et al. 2004). Strikingly, the nuclei from the three EC cell lines used in the study (F9, P19, METT-1) conferred their distinctive developmental and tumorigenic potentials to the resulting NT ES cells. This suggested that genetic alterations within the embryonic carcinoma nuclei were responsible for limiting the developmental potential of the NT ES lines. Consistent with this, comparative genomic hybridization showed shared and unique genetic alterations between the different EC cell lines. These findings support the notion that cancer results from the deregulation of stem cells and further suggest that the genetics of embryonic carcinomas will reveal genes involved in stem cell self-renewal and pluripotency.

Together, our findings demonstrate the general use of NT as a functional assay for characterizing commonalities among different types of cancer. Similarly, the nuclear transfer approach should be useful for the analysis of complex genetic disorders, such as diabetes and heart disease, in order to characterize and manipulate the multiple alleles affected in these diseases. At present, no other method has the power of amplifying the genome of a single cell with complex genetic alterations into a population of pluripotent ES cells.

\section{OUTLOOK: NUCLEAR REPROGRAMMING, CELLULAR PLASTICITY, AND THE PROSPECTIVE FOR CELL THERAPY}

Immune rejection is a frequent complication of allogeneic organ transplantation due to immunological incompatibility. To treat the "host versus graft" disease, immunosuppressive drugs are routinely given to transplant recipients, a treatment that has serious side effects. ES cells derived by nuclear transplantation are genetically identical to the patient's cells, thus eliminating the risk of immune rejection and the requirement for immunosuppression (Hochedlinger and Jaenisch 2003). Moreover, ES cells provide a renewable source of replacement tissue allowing for repeated therapy whenever needed. Indeed, we have recently demonstrated for the first time that NT could be combined with gene therapy to treat a genetic disorder (Fig. 6) (Rideout et al. 2002).

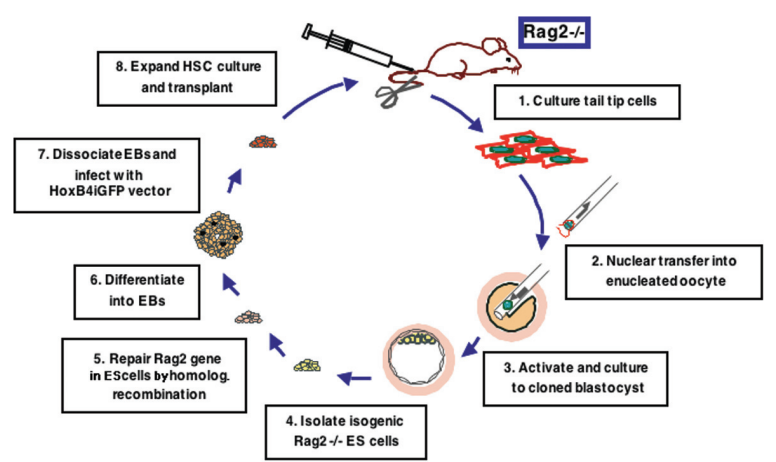

Figure 6. Scheme for therapeutic cloning combined with gene and cell therapy. A piece of tail from a mouse homozygous for the recombination activating gene 2 (Rag2) mutation was removed and cultured. After fibroblast-like cells grew out, they were used as donors for nuclear transfer by direct injection into enucleated MII oocytes using a piezoelectric-driven micromanipulator. Embryonic stem (ES) cells isolated from the NT-derived blastocysts were genetically repaired by homologous recombination. After repair, the ntES cells were differentiated in vitro into embryoid bodies (EBs), infected with the HoxB4iGFP retrovirus, expanded, and injected into the tail vein of irradiated, Rag2-deficient mice (see Rideout et al. 2002).

A key issue of transplantation medicine is the availability of isogenic functional cells that are of sufficiently high quality and can be obtained in large quantities. Therapeutic cloning would, in principle, solve this problem. Indeed, the recent generation of human embryonic stem cells by nuclear transfer into human eggs has provided evidence that this approach is a technically feasible strategy for the treatment of human disease (Hwang et al. 2004). Yet, serious obstacles such as the availability of human eggs and ethical considerations impede the application of therapeutic cloning for the treatment of patients suffering from disorders such as Parkinson's or diabetes. As an alternative approach adult stem cells have been proposed because numerous studies have claimed that these cells can give rise to many or all cells of the adult by a process designated as "transdifferentiation." However, the process of transdifferentiation is remarkably inefficient; some of the experimental claims have been difficult to reproduce or have alternative explanations (Terada et al. 2002; Ying et al. 2002; Alvarez-Dolado et al. 2003; Wang et al. 2003).

As depicted in Figure 7, the nuclear transplantation from a differentiated donor cell into the egg can alter the epigenetic state of the donor nucleus so that it is able to direct development of a new animal. This is accomplished by the action of reprogramming factors that are present in the egg's cytoplasm and that induce the genome to assume an epigenetic conformation appropriate for an embryonic state. It will be a major goal of future work to use the nuclear transfer technology as an experimental tool for defining the nature of the egg's reprogramming factors and the mechanisms of their action. Indeed, a recent report has demonstrated that Oct4 is reactivated in mammalian somatic nuclei after having been transplanted into Xeno- 


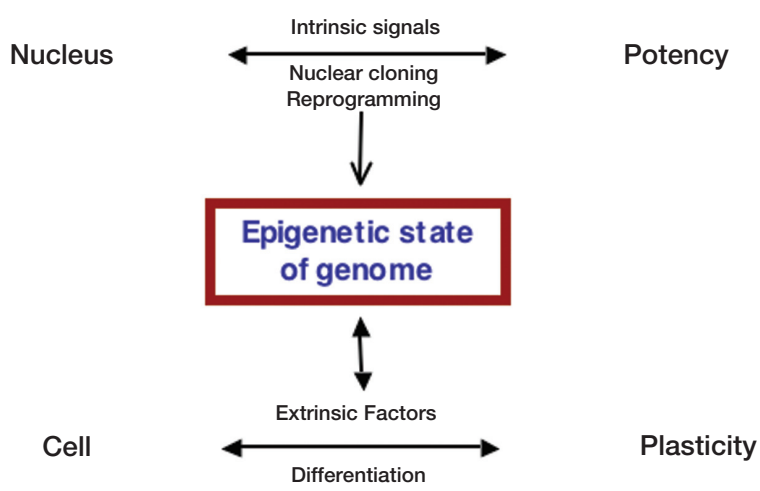

Figure 7. Epigenetic state of a genome determines nuclear potency and cellular plasticity. Nuclear transfer experiments have shown that factors within the oocyte can reprogram the epigenetic state of a differentiated cell into that of an embryonic cell, thus increasing the developmental potency of its nucleus. A better understanding of the factors that direct epigenetic reprogramming may allow us to directly alter the epigenetic state of differentiated cells and turn them into embryonic stem cells for use in cell replacement therapy.

pus oocytes (Byrne et al. 2003). Thus, it may be possible to understand the molecular basis of epigenetic reprogramming and to establish rational strategies for altering the potential of somatic cells (compare Fig. 1). The hope would be that such an approach eventually would allow the reprogramming of a patient's cells into different embryonic stem cells that could be used for cell replacement therapy without the need for nuclear transplantation.

\section{ACKNOWLEDGMENTS}

The work summarized in this article has been supported by grants from the National Institutes of Health.

\section{REFERENCES}

Alvarez-Dolado M., Pardal R., Garcia-Verdugo J.M., Fike J.R., Lee H.O., Pfeffer K., Lois C., Morrison S.J., and AlvarezBuylla A. 2003. Fusion of bone-marrow-derived cells with Purkinje neurons, cardiomyocytes and hepatocytes. Nature 425: 968

Betts D., Bordignon V., Hill J., Winger Q., Westhusin M., Smith L., and King W. 2001. Reprogramming of telomerase activity and rebuilding of telomere length in cloned cattle. Proc. Natl. Acad. Sci. 98: 1077.

Blelloch R., Hochedlinger K., Yamado Y., Brennan C., Kim M., Mintz B., Chin L., and Jaenisch R. 2004. Nuclear cloning of embryonal carcinoma cells. Proc. Natl. Acad. Sci. 101: 14305.

Boiani M., Eckardt S., Scholer H.R., and McLaughlin K.J. 2002. Oct4 distribution and level in mouse clones: Consequences for pluripotency. Genes Dev. 16: 1209.

Bortvin A., Eggan K., Skaletsky H., Akutsu H., Berry D.L., Yanagimachi R., Page D.C., and Jaenisch R. 2003. Incomplete reactivation of Oct4-related genes in mouse embryos cloned from somatic nuclei. Development 130: 1673.

Bourc'his D., Le Bourhis D., Patin D., Niveleau A., Comizzoli P., Renard J.P., and Viegas-Pequignot E. 2001. Delayed and incomplete reprogramming of chromosome methylation patterns in bovine cloned embryos. Curr. Biol. 11: 1542.

Byrne J.A., Simonsson S., Western P.S., and Gurdon J.B. 2003. Nuclei of adult mammalian somatic cells are directly repro- grammed to oct- 4 stem cell gene expression by amphibian oocytes. Curr. Biol. 13: 1206.

Carlson D.L., Sauerbier W., Rollins-Smith L.A., and McKinnell R.G. 1994. Fate of herpesvirus DNA in embryos and tadpoles cloned from Lucké renal carcinoma nuclei. J. Comp. Pathol. 111: 197.

Chun J. and Schatz D.G. 1999. Rearranging views on neurogenesis: Neuronal death in the absence of DNA end-joining proteins. Neuron 22: 7.

Daniels R., Hall Y., and Trounson A. 2000. Analysis of gene transcription in bovine nuclear transfer embryos reconstructed with granulosa cell nuclei. Biol. Reprod. 63: 1034.

Dean W., Santos F., and Reik W. 2003. Epigenetic reprogramming in early mammalian development and following somatic nuclear transfer. Semin. Cell Dev. Biol. 14: 93.

Dean W., Santos F., Stojkovic M., Zakhartchenko V., Walter J., Wolf E., and Reik W. 2001. Conservation of methylation reprogramming in mammalian development: Aberrant reprogramming in cloned embryos. Proc. Natl. Acad. Sci. 98: 13734.

Di Berardino M.A. 1980. Genetic stability and modulation of metazoan nuclei transplanted into eggs and oocytes. Differentiation 17: 17.

Di Berardino M.A., McKinnell R.G., and Wolf D.P. 2003. The golden anniversary of cloning: A celebratory essay. Differentiation 71: 398

Eggan K., Akutsu H., Hochedlinger K., Rideout W., Yanagimachi R., and Jaenisch R. 2000. X-chromosome inactivation in cloned mouse embryos. Science 290: 1578.

Eggan K., Akutsu H., Loring J., Jackson-Grusby L., Klemm M., Rideout W.M., III, Yanagimachi R., and Jaenisch R. 2001. Hybrid vigor, fetal overgrowth, and viability of mice derived by nuclear cloning and tetraploid embryo complementation. Proc. Natl. Acad. Sci. 98: 6209.

Eggan K., Baldwin K., Tackett M., Osborne J., Gogos J., Chess A., Axel R., and Jaenisch R. 2004. Mice cloned from olfactory sensory neurons. Nature 428: 44.

Felsher D.W. 2003. Cancer revoked: Oncogenes as therapeutic targets. Nat. Rev. Cancer 3: 375.

Ferguson-Smith A.C. and Surani M.A. 2001. Imprinting and the epigenetic asymmetry between parental genomes. Science 293: 1086.

Fulka J., Jr., Miyashita N., Nagai T., and Ogura A. 2004. Do cloned mammals skip a reprogramming step? Nat. Biotechnol. 22: 25 .

Gurdon J.B. 1999. Genetic reprogramming following nuclear transplantation in Amphibia. Semin. Cell Dev. Biol. 10: 239.

Hochedlinger K. and Jaenisch R. 2002a. Monoclonal mice generated by nuclear transfer from mature $\mathrm{B}$ and $\mathrm{T}$ donor cells. Nature 415: 1035.

. 2002b. Nuclear transplantation: Lessons from frogs and mice. Curr. Opin. Cell Biol. 14: 741

. 2003. Nuclear transplantation, embryonic stem cells, and the potential for cell therapy. N. Engl. J. Med. 349: 275.

Hochedlinger K., Blelloch R., Brennan C., Yamada Y., Kim M., Chin L., and Jaenisch R. 2004. Reprogramming of a melanoma genome by nuclear transplantation. Genes Dev. 18: 1875 .

Humpherys D., Eggan K., Akutsu H., Friedman A., Hochedlinger K., Yanagimachi R., Lander E., Golub T.R., and Jaenisch R. 2002. Abnormal gene expression in cloned mice derived from ES cell and cumulus cell nuclei. Proc. Natl. Acad. Sci. 99: 12889.

Hwang W.S., Ryu Y.J., Park J.H., Park E.S., Lee E.G., Koo J.M., Jeon H., Lee B.C., Kang S.K., Kim S.J., Ahn C., Hwang J.H., Park K.Y., Cibelli J.B., and Moon S.Y. 2004. Evidence of a pluripotent human embryonic stem cell line derived from a cloned blastocyst. Science 303: 1669.

Jaenisch R. 1997. DNA methylation and imprinting: Why bother? Trends Genet. 13: 323.

. 2004. The biology of nuclear cloning and the potential of embryonic stem cells for transplantation therapy. The President's Council on Bioethics: http://www.bioethics.gov/ reports/stemcell/appendix_n.html.

Jaenisch R. and Bird A. 2003. Epigenetic regulation of gene ex- 
pression: How the genome integrates intrinsic and environmental signals. Nat. Genet. (suppl.) 33: 245.

Jaenisch R., Hochedlinger K., and Eggan K. 2004. Stem cells, nuclear cloning and the epigenetic state of the genome. In Stem cells: Nuclear reprogramming and therapeutic applications (ed. J. Gearhart). Novartis Foundation Symposium. (In press.)

Jones P.A. and Baylin S.B. 2002. The fundamental role of epigenetic events in cancer. Nat. Rev. Genet. 3: 415.

Kang Y., Koo J., Park J., Choi Y., Chung A., Lee K., and Han Y. 2001. Aberrant methylation of donor genome in cloned bovine embryos. Nat. Genet. 28: 173.

Kang Y.K., Park J.S., Koo D.B., Choi Y.H., Kim S.U., Lee K.K., and Han Y.M. 2002. Limited demethylation leaves mosaictype methylation states in cloned bovine pre-implantation embryos. EMBO J. 21: 1092 .

Lanza R.P., Cibelli J.B., Faber D., Sweeney R.W., Henderson B., Nevala W., West M.D., and Wettstein P.J. 2001. Cloned cattle can be healthy and normal. Science 294: 1893.

Lanza R.P., Cibelli J.B., Blackwell C., Cristofalo V.J., Francis M.K., Baerlocher G.M., Mak J., Schertzer M., Chavez E.A., Sawyer N., Lansdorp P.M., and West M.D. 2000. Extension of cell life-span and telomere length in animals cloned from senescent somatic cells. Science 288: 665 .

Latham K.E. 1999. Mechanisms and control of embryonic genome activation in mammalian embryos. Int. Rev. Cytol. 193: 71.

Li E. 2002. Chromatin modification and epigenetic reprogramming in mammalian development. Nat. Rev. Genet. 3: 662

Li J., Ishii T., Feinstein P., and Mombaerts P. 2004. Odorant receptor gene choice is reset by nuclear transfer from mouse olfactory sensory neurons. Nature 428: 393.

Li L., Connelly M.C., Wetmore C., Curran T., and Morgan J.I. 2003. Mouse embryos cloned from brain tumors. Cancer Res. 63: 2733.

Liu L. 2001. Cloning efficiency and differentiation. Nat. Biotechnol. 19: 406.

Mann M.R., Chung Y.G., Nolen L.D., Verona R.I., Latham K.E., and Bartolomei M.S. 2003. Disruption of imprinted gene methylation and expression in cloned preimplantation stage mouse embryos. Biol. Reprod. 69: 902.

Mayer W., Niveleau A., Walter J., Fundele R., and Haaf T. 2000. Demethylation of the zygotic paternal genome. Nature 403: 501.

McKinnell R.G., Deggins B.A., and Labat D.D. 1969. Transplantation of pluripotential nuclei from triploid frog tumors. Science 165: 394.

Monk M., Boubelik M., and Lehnert S. 1987. Temporal and regional changes in DNA methylation in the embryonic, extraembryonic and germ cell lineages during mouse embryo development. Development 99: 371.

Nagy A., Rossant J., Nagy R., Abramow-Newerly W., and Roder J.C. 1993. Derivation of completely cell culture-derived mice from early-passage embryonic stem cells. Proc. Natl. Acad. Sci. 90: 8424.

Nichols J., Zevnik B., Anastassiadis K., Niwa H., Klewe-Nebenius D., Chambers I., Scholer H., and Smith A. 1998. Formation of pluripotent stem cells in the mammalian embryo depends on the POU transcription factor Oct4. Cell 95: 379.

Oback B. and Wells D. 2002. Donor cells for cloning: Many are called but few are chosen. Cloning Stem Cells 4: 147.

Ogonuki N., Inoue K., Yamamoto Y., Noguchi Y., Tanemura K., Suzuki O., Nakayama H., Doi K., Ohtomo Y., Satoh M., Nishida A., and Ogura A. 2002. Early death of mice cloned from somatic cells. Nat. Genet. 30: 253.
Oswald J., Engemann S., Lane N., Mayer W., Olek A., Fundele R., Dean W., Reik W., and Walter J. 2000. Active demethylation of the paternal genome in the mouse zygote. Curr. Biol. 10: 475 .

Rehen S.K., McConnell M.J., Kaushal D., Kingsbury M.A., Yang A.H., and Chun J. 2001. Chromosomal variation in neurons of the developing and adult mammalian nervous system. Proc. Natl. Acad. Sci. 98: 13361.

Reik W., Dean W., and Walter J. 2001. Epigenetic reprogramming in mammalian development. Science 293: 1089.

Rideout W.M., Eggan K., and Jaenisch R. 2001. Nuclear cloning and epigenetic reprogramming of the genome. Science 293: 1093.

Rideout W.M., III, Hochedlinger K., Kyba M., Daley G.Q., and Jaenisch R. 2002. Correction of a genetic defect by nuclear transplantation and combined cell and gene therapy. Cell 109: 17.

Rossant J. 2002. A monoclonal mouse? Nature 415: 967.

Santos F., Hendrich B., Reik W., and Dean W. 2002. Dynamic reprogramming of DNA methylation in the early mouse embryo. Dev. Biol. 241: 172.

Tamashiro K.L., Wakayama T., Akutsu H., Yamazaki Y., Lachey J.L., Wortman M.D., Seeley R.J., D’Alessio D.A., Woods S.C., Yanagimachi R., and Sakai R.R. 2002. Cloned mice have an obese phenotype not transmitted to their offspring. Nat. Med. 8: 262.

Terada N., Hamazaki T., Oka M., Hoki M., Mastalerz D.M., Nakano Y., Meyer E.M., Morel L., Petersen B.E., and Scott E.W. 2002. Bone marrow cells adopt the phenotype of other cells by spontaneous cell fusion. Nature 416: 542 .

Tian X.C., Xu J., and Yang X. 2000. Normal telomere lengths found in cloned cattle. Nat. Genet. 26: 272.

Vassar R., Ngai J., and Axel R. 1993. Spatial segregation of odorant receptor expression in the mammalian olfactory epithelium. Cell 74: 309.

Wakayama T. and Yanagimachi R. 1999. Cloning of male mice from adult tail-tip cells. Nat. Genet. 22: 127.

. 2001. Mouse cloning with nucleus donor cells of different age and type. Mol. Reprod. Dev. 58: 376.

Wakayama T., Shinkai Y., Tamashiro K.L., Niida H., Blanchard D.C., Blanchard R.J., Ogura A., Tanemura K., Tachibana M., Perry A.C., Colgan D.F., Mombaerts P., and Yanagimachi R. 2000. Cloning of mice to six generations. Nature 407: 318.

Wang X., Willenbring H., Akkari Y., Torimaru Y., Foster M., Al-Dhalimy M., Lagasse E., Finegold M., Olson S., and Grompe M. 2003. Cell fusion is the principal source of bonemarrow-derived hepatocytes. Nature 422: 897.

Wilmut I., Schnieke A.E., McWhir J., Kind A.J., and Campbell K.H. 1997. Viable offspring derived from fetal and adult mammalian cells. Nature 385: 810.

Yamazaki Y., Makino H., Hamaguchi-Hamada K., Hamada S., Sugino H., Kawase E., Miyata T., Ogawa M., Yanagimachi R., and Yagi T. 2001. Assessment of the developmental totipotency of neural cells in the cerebral cortex of mouse embryo by nuclear transfer. Proc. Natl. Acad. Sci. 98: 14022 .

Ying Q.L., Nichols J., Evans E.P., and Smith A.G. 2002. Changing potency by spontaneous fusion. Nature 416: 545 .

Young L.E., Sinclair K.D., and Wilmut I. 1998. Large offspring syndrome in cattle and sheep. Rev. Reprod. 3: 155.

Zhang X. and Firestein S. 2002. The olfactory receptor gene superfamily of the mouse. Nat. Neurosci. 5: 124. 


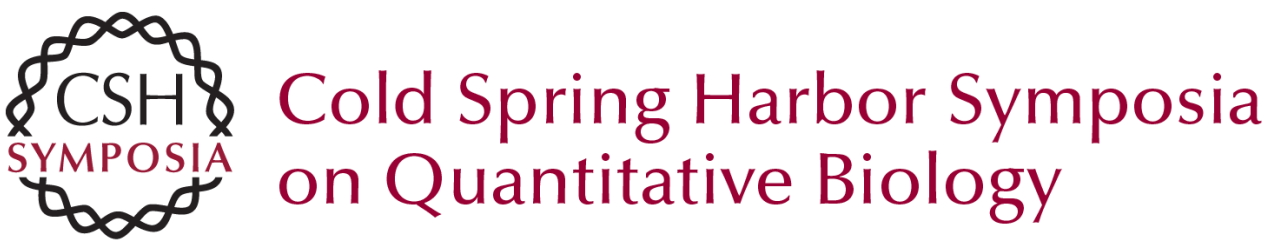

\section{Nuclear Cloning, Epigenetic Reprogramming, and Cellular Differentiation}

R. JAENISCH, K. HOCHEDLINGER, R. BLELLOCH, et al.

Cold Spring Harb Symp Quant Biol 2004 69: 19-28

Access the most recent version at doi:10.1101/sqb.2004.69.19

References This article cites 67 articles, 22 of which can be accessed free at: http://symposium.cshlp.org/content/69/19.full.html\#ref-list-1

License

Email Alerting Receive free email alerts when new articles cite this article - sign up in Service the box at the top right corner of the article or click here. 